\title{
THERMODYNAMIC PROPERTIES OF BINARY LIQUID MIXTURE OF CARBON TETRACHLORIDE- 0 -XYLENE AT THREE DIFFERENT TEMPERATURES
}

\author{
Venkatesan D. ${ }^{1, *}$ and Joshua Amarnath D. ${ }^{1}$ \\ ${ }^{1}$ Department of Chemical Engineering, Sathyabama Institute of Science and Technology, \\ Chennai-600119, India \\ *E-mail: venkatesaniitkgp@gmail.com
}

\begin{abstract}
The thermodynamic properties of the binary liquid mixture carbon tetrachloride and o-xylene were studied at $\mathrm{T}$ $(303.15 \mathrm{~K}, 313.15 \mathrm{~K}$, and $323.15 \mathrm{~K})$ and at $1 \mathrm{~atm}$. The thermodynamic properties, viscosity- $\eta$, density- $\rho$, and refractive index- $\mathrm{n}_{\mathrm{D}}$ are studied. The $\mathrm{V}^{\mathrm{E}}, \Delta \eta, \Delta \mathrm{n}_{\mathrm{D}}$, and $\Delta \mathrm{G}^{* \mathrm{E}}$ were estimated from the experimental data. The Redlich-Kister model was employed to correlate the deviations of thermodynamic properties. The interactions in the binary system were quantitatively analyzed using modified Kendall-Monroe equation $\left(\mathrm{E} \prod_{\mathrm{m}}\right)$. In this work all the experimental data were correlated and close-fitting with the thermodynamic models. The results obtained were also concluded based on the interactions of the binary mixture.
\end{abstract}

Keywords: Density, Viscosity, Refractive index, Carbon tetrachloride, o-xylene

(C) RASĀYAN. All rights reserved

\section{INTRODUCTION}

The study of thermophysical properties of fluids are essential to understanding the molecular interactions and it facilitates the design of many industrial chemical processes involving heat, mass and fluid flow ${ }^{1}$ The deviations arising in thermodynamic and transport properties are very complex due to interactions between the solute-solute, solvent-solvent, and solute-solvent ${ }^{2}$ and the interstitial accommodation due to structural effects. A quantifiable estimation of liquid mixtures is required to design the mass transfer operations. In many industrial applications, Carbon Tetrachloride is used as a solvent for oil and fats, as a refrigerant, fire suppressing agent, and dry-cleaning agent. O-xylene is a commonly used compound in the manufacture of paint, varnish, dyes, and rubber. Recently there has been a considerable progress in the studies on intermolecular interactions in fluid mixtures. In the earlier experimental studies, it is reported that the thermophysical properties of binary liquid system ${ }^{3-6}$. In this present study, it is reported that the viscosity, density, and Refractive index for the binary liquid mixture that contains carbon tetrachloride and o-xylene at $\mathrm{T}(303.15 \mathrm{~K}$ to $323.15 \mathrm{~K})$. Using the viscosity $(\eta)$,density $(\rho)$, and refractive index $\left(\mathrm{n}_{\mathrm{D}}\right)$ data, the deviations in viscosity $(\Delta \eta)$, excess molar volume $\left(\mathrm{V}^{\mathrm{E}}\right)$, excess Gibbs free energy $\left(\Delta \mathrm{G}^{*} \mathrm{E}\right)$ are obtained and presented. The Redlich-Kister ${ }^{7}$ model is employed to fit the studied properties of liquid mixtures and the results were analyzed based on the molecular interactions.

\section{EXPERIMENTAL}

In the present study, the chemicals used were all of the analytical grades with purity of $\geq 0.998$ in mass fraction and was purchased from Lobo Chemicals, India. Prior to the use of these chemicals, they were pretreated by standard method ${ }^{8,9}$. The solvent purity in this study was determined by relating their viscosities, densities, and refractive indices with the conforming literature values at $\mathrm{T} 303.15 \mathrm{~K}$ and it was given in table 1. Electronic balance (Model: BL 2205) with a precision of $\pm 0.001 \mathrm{mg}$ was supplied by Shimadzu Corporation, Japan was used to prepare the binary liquid mixture (Carbon tetrachloride- $o$ xylene). Immediately, after preparing each composition of liquid mixtures the required properties were measured. In all the experimental measurements, the temperature fluctuations were controlled and maintained within $\pm 0.03 \mathrm{~K}$ through the circulation of water through the thermostat (Technico, India). 


\section{Density}

The density of pure component and the mixtures were measured using capillary Pycnometer. The procedure was standardized with the help of deionized water with a density of $996 \mathrm{~kg} / \mathrm{m}^{3}$ at $303.15 \mathrm{~K}$. The Pycnometer was placed in the thermostat water bath where the temperature was maintained constant to \pm $0.01 \mathrm{~K}$ for about 15 minutes in order to attain the thermal equilibrium, and traveling microscope was used to obtain the liquid level in two arms of Pycnometer. The density measurement precision was estimated as $\pm 0.3 \mathrm{~kg} / \mathrm{m}^{3}$

\section{Viscosity}

The Ostwald viscometer was used to measure the viscosity of liquid chemicals in pure and mixtures state. A correctness of $0.01 \mathrm{~s}$ was associated with the time in viscosity measurement and the $<0.0002 \mathrm{mPa}$.s was the estimated uncertainty in the $\eta$-viscosity obtained from the relation given below:

$$
\eta=(a t-b / t) \rho
$$

In the above equation 1 , the viscometer characteristic constants are ' $a$ ' and ' $b$ ', the density $\rho$ and the flow time is ' $t$ '. For five times, the pure liquids and binary liquid mixtures flow times were repeated.

\section{Refractive Index}

An Abbe refractometer $(<0.0001$ units in accuracy) with thermostatic control was used to measure the refractive indices. The temperature in the refractometer was maintained constantly by circulation of water through the prism by a recirculation pump which was associated with the external water bath thermostat. Refractive indices- $n_{D}$ of double condensed water and other suitable solvents at definite temperatures were used for standardization. A syringe was used to inject the sample mixtures into the refractometer prism assembly. In order to achieve faster thermal equilibrium, the solutions were pre-thermostated before the experiments.

\section{RESULTS AND DISCUSSION}

The experimental data obtained for the liquid mixtures from the present study was compared with existing literature data and are given in the Table-1. The viscosity data from the correlation was proposed by Singh ${ }^{10}$ that was used to estimate the $V^{E}$ of the binary mixtures (carbon tetrachloride and o-xylene) by eqn.-2.

$$
\Delta \eta=k \times V^{E}
$$

In the above relation, the fitting parameter is $k$. The $k$ mixtures were scrutinized in the present study and were evaluated with the help of experimentally reported $(\Delta \eta)$, and $\left(V^{E}\right)$ data. The densities, viscosities and refractive indices were obtained from the experiments at three different temperatures for the entire mole fractions range were listed in the Table- 2 .

Table-1: Comparison of the literature and experimental data of $\rho, \eta$ and $n_{D}$ of a pure substance at $303.15 \mathrm{~K}$ along with the fitting parameters.

\begin{tabular}{l|c|c|c|c|c|c}
\hline \multirow{2}{*}{$\begin{array}{c}\text { Pure } \\
\text { Liquids }\end{array}$} & \multicolumn{2}{|c|}{$\rho \times 10^{-3}\left(\mathrm{~kg} \mathrm{~m}^{-3}\right)$} & \multicolumn{2}{c|}{$\eta(\mathrm{mPa} . \mathrm{s})$} & \multicolumn{2}{c}{$\mathrm{n}_{\mathrm{D}}$} \\
\cline { 2 - 7 } & Lit. & Exp. & Lit. & Exp. & Lit. & Exp. \\
\hline \multirow{4}{*}{ Carbon tetrachloride } & $1.5750^{11}$ & & $0.8403^{11}$ & & $1.4998^{14}$ & \\
& $1.5775^{12}$ & 1.5743 & $0.8300^{12}$ & 0.8450 & $1.4932^{15}$ & 1.4980 \\
& $1.5748^{13}$ & & $0.8441^{13}$ & & $1.5000^{16}$ & \\
\hline \multirow{4}{*}{ o-xylene } & $0.8707^{16}$ & & $0.7080^{17}$ & & & \\
& $0.8714^{14}$ & & $0.7096^{20}$ & & $1.4511^{19}$ & \\
& $0.8709^{17}$ & 0.8718 & $0.7150^{14}$ & 0.7090 & $1.4555^{13}$ & 1.4504 \\
& $0.8711^{18}$ & & $0.6950^{16}$ & & & \\
\hline
\end{tabular}


RASĀYAN J. Chem.

Vol. 11 | No. 2 |834 - 843 | April - June | 2018

\begin{tabular}{c|c|c|c|c|c|c}
\hline Temperature $(\mathrm{K})$ & 303.15 & 313.15 & 323.15 & & & \\
\hline Fitting Parameter $(k)$ & -0.004542 & -0.00299 & -0.00243 & & & \\
\hline
\end{tabular}

Table-2: $\rho, \eta$, and $\mathrm{n}_{\mathrm{D}}$ of carbon tetrachloride (1) +o-xylene (2) mixture

\begin{tabular}{c|c|c|c|c|c|c|c|c|c}
\hline \multicolumn{5}{c}{$\rho \times 10^{-3}\left(\mathrm{~kg} \mathrm{~m}^{-3}\right)$} & \multicolumn{3}{c|}{$\eta(\mathrm{mPa} . \mathrm{s})$} & \multicolumn{3}{c}{$\mathrm{n}_{\mathrm{D}}$} \\
\cline { 1 - 9 } $\mathrm{T} / \mathrm{K}$ & 303.15 & 313.15 & 323.15 & 303.15 & 313.15 & 323.15 & 303.15 & 313.15 & 323.15 \\
\hline$x_{1}$ & & & & & & & & & \\
\hline 0.0000 & 0.8718 & 0.8636 & 0.8553 & 0.7090 & 0.6250 & 0.5556 & 1.4980 & 1.4978 & 1.4889 \\
\hline 0.1220 & 0.9423 & 0.9331 & 0.9239 & 0.7243 & 0.6379 & 0.5666 & 1.4932 & 1.4924 & 1.4839 \\
\hline 0.2381 & 1.0127 & 1.0026 & 0.9924 & 0.7392 & 0.6505 & 0.5772 & 1.4885 & 1.4870 & 1.4789 \\
\hline 0.3489 & 1.0830 & 1.0720 & 1.0609 & 0.7538 & 0.6627 & 0.5875 & 1.4837 & 1.4817 & 1.4739 \\
\hline 0.4546 & 1.1533 & 1.1414 & 1.1292 & 0.7679 & 0.6746 & 0.5976 & 1.4790 & 1.4763 & 1.4689 \\
\hline 0.5556 & 1.2236 & 1.2106 & 1.1974 & 0.7816 & 0.6862 & 0.6073 & 1.4742 & 1.4709 & 1.4639 \\
\hline 0.6522 & 1.2938 & 1.2798 & 1.2655 & 0.7950 & 0.6974 & 0.6168 & 1.4694 & 1.4655 & 1.4588 \\
\hline 0.7447 & 1.3640 & 1.3489 & 1.3335 & 0.8080 & 0.7084 & 0.6260 & 1.4647 & 1.4601 & 1.4538 \\
\hline 0.8334 & 1.4342 & 1.4179 & 1.4014 & 0.8206 & 0.7190 & 0.6350 & 1.4599 & 1.4548 & 1.4488 \\
\hline 0.9184 & 1.5043 & 1.4869 & 1.4692 & 0.8330 & 0.7294 & 0.6437 & 1.4552 & 1.4494 & 1.4438 \\
\hline 1.0000 & 1.5743 & 1.5558 & 1.5368 & 0.8450 & 0.7394 & 0.6521 & 1.4504 & 1.4440 & 1.4388 \\
\hline
\end{tabular}

The following equation was used to evaluate the $V^{\mathrm{E}}$

$$
V^{E}=\frac{x_{1} M_{1}+x_{2} M_{2}}{\rho_{m}}-\frac{x_{1} M_{1}}{\rho_{1}}-\frac{x_{\mathrm{n}} M_{\mathrm{n}}}{\rho_{\mathrm{n}}}
$$

In the above relation, the $x_{1}$ and $x_{2}$ are the mole fraction of carbon tetrachloride and o-xylene. The density of respective component in pure and the mixture density are $\rho_{1}, \rho_{2}$, and $\rho_{\mathrm{m}}$ respectively. The uncertainty in $V^{\mathrm{E}}$ calculations from the measurements density is estimated to be \pm 0.0001 . The relationship given in eqn.-4 is used to calculate the $\Delta \eta$ (viscosity deviations)

$$
\Delta \eta=\eta-\left(x_{1} \eta_{1}+x_{2} \eta_{2}\right)
$$

In the above eqn.-4, the mixture viscosity- $\eta$, the viscosity of carbon tetrachloride- $\eta_{1}$, and viscosity of oxylene- $\eta_{2}$. In $\Delta \eta$ calculations from the viscosity measurements, the uncertainty is estimated to be \pm 0.0001 . There are many models available in the literature to determine mixtures viscosity that is based on the pure component data. To perform a comprehensive analysis, the models proposed ${ }^{21-26}$ are used to determine the viscosity of carbon tetrachloride (1) and o-xylene (2).

1. Based on zero adjustable parameters, Kendall-Monroe ${ }^{21}$ derived the equation 5 for the analysis of viscosity of binary mixtures. This equation computes viscosity of mixture as the cubic-root average of the component viscosities:

$$
\eta=\left(\eta_{1} x_{1}^{1 / 3}+\eta_{2} x_{2}^{1 / 3}\right)^{3}
$$

2. Considering the interaction between the molecules, a logarithmic model for non-ideal binary mixture was developed by Frenkel with the help of Eyring's model ${ }^{22,23}$ is given below:

$$
\ln (\eta)=\mathrm{x}_{1}^{2} \ln \left(\eta_{1}\right)+\mathrm{x}_{2}^{2} \ln \left(\eta_{2}\right)+2 \mathrm{x}_{1} \mathrm{x}_{2} \ln \left(\eta_{12}\right)
$$


The value of $\eta_{12}$, a constant which is ascribed to dissimilar pair interactions is found from the following equation:

$$
\eta_{12}=0.5 \eta_{1}+0.5 \eta_{2}
$$

3. The model given below is suggested by Hind et al. ${ }^{24}$

$$
\ln (\eta)=\mathrm{x}_{1}^{2} \eta_{1}+\mathrm{x}_{2}^{2} \eta_{2}+2 \mathrm{x}_{1} \mathrm{x}_{2} \mathrm{H}_{12}
$$

The interaction parameter by Hind et al. in the above model is given $\mathrm{H}_{12}$ and it is ascribed to, unlike pair interactions.

4. The equation proposed by Katti-Chaudhri ${ }^{25}$ is expressed as:

$$
\ln (\eta V)=x_{1} \ln \left[\eta_{1} V_{1}\right]+x_{2} \ln \left[\eta_{2} V_{2}\right]+\mathrm{x}_{1} \mathrm{x}_{2}(\mathrm{~W} / \mathrm{RT})
$$

In the above eqn.-9, interaction energy parameter is $\mathrm{W}$, the mixture volume $V$, the volumes of carbon tetrachloride and o-xylene are $V_{1}$ and $V_{2}$ respectively.

5. Grunberg and Nissan ${ }^{26}$ have formulated an equation to review the molecular interactions directing to viscosity changes:

$$
\ln (\eta)=\mathrm{x}_{1} \ln \left(\eta_{1}\right)+\mathrm{x}_{2} \ln \left(\eta_{2}\right)+\mathrm{x}_{1} \mathrm{x}_{2} G_{12}
$$

In the above eqn.-10, $\mathrm{G}_{12}$ is constant that is proportional to interchange energy, the dynamic viscosity is $\eta$ and 1, 2 and 12 subscripts stands for the pure components, carbon tetrachloride, o-xylene, and mixtures, respectively.

The predicted viscosity values of the studied binary mixtures using equations-(5), (6), (7), (8), (9) and (10), at three different temperatures are compared with the experimentally measured values, and results are given in Table-3 is based on $\Delta \eta$ (viscosity deviations) .

Table-3: Viscosity Deviation $\left(\eta_{\exp }-\eta_{\text {cal }}\right)$ for the Binary Mixtures

\begin{tabular}{l|l|l|l|l|l}
\hline$x_{1}$ & Frenkel & Hind & Katti & G. \& N. & K. \& M. \\
\hline \multicolumn{7}{|c}{$303.15 \mathrm{~K}$} \\
\hline 0.0000 & -0.3439 & - & - & - & 0.7090 \\
\hline 0.1220 & -0.3217 & 0.7710 & 3.4858 & -0.0005 & 0.7247 \\
\hline 0.2381 & -0.3007 & 0.7710 & 3.0492 & -0.0004 & 0.7399 \\
\hline 0.3489 & -0.2809 & 0.7712 & 2.8717 & 0.0002 & 0.7546 \\
\hline 0.4546 & -0.2622 & 0.7711 & 2.8038 & 0.0001 & 0.7689 \\
\hline 0.5556 & -0.2445 & 0.7710 & 2.8073 & 0.0000 & 0.7826 \\
\hline 0.6522 & -0.2277 & 0.7710 & 2.8738 & 0.0002 & 0.7959 \\
\hline 0.7447 & -0.2118 & 0.7710 & 3.0139 & 0.0001 & 0.8088 \\
\hline 0.8334 & -0.1966 & 0.7708 & 3.2699 & -0.0004 & 0.8212 \\
\hline 0.9184 & -0.1822 & 0.7710 & 3.7983 & 0.0003 & 0.8333 \\
\hline 1.0000 & -0.1684 & - & - & - & 0.8450 \\
\hline \multicolumn{7}{|c}{} \\
\hline 0.0000 & -0.4700 & - & - & - & 0.6250 \\
\hline
\end{tabular}


RASĀYAN J. Chem.

Vol. 11 | No. 2 |834 - 843 | April - June | 2018

\begin{tabular}{l|l|l|l|l|l}
\hline 0.1220 & -0.4487 & 0.6773 & 3.4856 & -0.0007 & 0.6383 \\
\hline 0.2381 & -0.4287 & 0.6774 & 3.0494 & -0.0002 & 0.6511 \\
\hline 0.3489 & -0.4098 & 0.6773 & 2.8711 & -0.0003 & 0.6635 \\
\hline 0.4546 & -0.3918 & 0.6774 & 2.8035 & -0.0002 & 0.6754 \\
\hline 0.5556 & -0.3749 & 0.6774 & 2.8074 & 0.0001 & 0.6870 \\
\hline 0.6522 & -0.3588 & 0.6773 & 2.8736 & -0.0001 & 0.6982 \\
\hline 0.7447 & -0.3435 & 0.6775 & 3.0142 & 0.0004 & 0.7090 \\
\hline 0.8334 & -0.3289 & 0.6774 & 3.2705 & 0.0002 & 0.7194 \\
\hline 0.9184 & -0.3151 & 0.6778 & 3.7994 & 0.0014 & 0.7296 \\
\hline 1.0000 & -0.3019 & - & - & - & 0.7394 \\
\hline & & & & \\
\hline 0.0000 & -0.5877 & - & - & - & 0.5556 \\
\hline 0.1220 & -0.5675 & 0.6003 & 3.4870 & 0.0007 & 0.5668 \\
\hline 0.2381 & -0.5484 & 0.6001 & 3.0496 & 0.0000 & 0.5776 \\
\hline 0.3489 & -0.5304 & 0.6000 & 2.8712 & -0.0002 & 0.5881 \\
\hline 0.4546 & -0.5133 & 0.6001 & 2.8040 & 0.0003 & 0.5982 \\
\hline 0.5556 & -0.4971 & 0.6000 & 2.8073 & 0.0000 & 0.6079 \\
\hline 0.6522 & -0.4818 & 0.6000 & 2.8739 & 0.0002 & 0.6174 \\
\hline 0.7447 & -0.4672 & 0.6000 & 3.0140 & 0.0002 & 0.6265 \\
\hline 0.8334 & -0.4534 & 0.6002 & 3.2711 & 0.0008 & 0.6353 \\
\hline 0.9184 & -0.4401 & 0.6004 & 3.7995 & 0.0014 & 0.6438 \\
\hline 1.0000 & -0.4276 & - & - & - & 0.6521 \\
\hline
\end{tabular}

The excess Gibbs free energy- $\Delta \mathrm{G}^{* \mathrm{E}}{ }^{27}$, based on the theory of absolute reaction rates, are computed by using the following model:

$$
\Delta G^{* E}=R T\left[\ln (\eta V)-x_{1} \ln \left(\eta_{1} V_{1}\right)-x_{2} \ln \left(\eta_{2} V_{2}\right)\right]
$$

Where $R$ is a universal gas constant, $T$ is the temperature, $V, V_{1}$, and $V_{2}$ are molar volumes of the mixture, the molar volume of respective components 1 and 2.

The variations in refractive index $\left(\Delta \mathrm{n}_{\mathrm{D}}\right)$ is calculated by using equation (12).

$$
\Delta n_{D}=n_{D}-\left(x_{1} n_{D 1}+x_{2} n_{D 2}\right)
$$

The $\Delta \eta, \mathrm{V}^{\mathrm{E}}, \Delta n_{D}, \Delta \mathrm{G}^{* E}$ and $E \prod_{m}$ of the carbon tetrachloride and $o$-xylene mixtures are presented in Table4.

Table-4: The $\Delta \eta, \mathrm{V}^{\mathrm{E}}, \Delta n_{D}, \Delta \mathrm{G}^{*} E$ and $E \prod_{m}$ of the carbon tetrachloride (1) + o-xylene (2) mixture at $\mathrm{T}$ in $\mathrm{K}$.

\begin{tabular}{c|c|c|c|c|c}
\hline$x_{1}$ & $\begin{array}{c}\Delta \eta \\
(\mathrm{mPa} . \mathrm{s})\end{array}$ & $\begin{array}{c}V^{E} \times 10^{6} \\
\left(\mathrm{~m}^{3} \mathrm{~mol}^{-1}\right)\end{array}$ & $\Delta n_{D}$ & $\begin{array}{c}\Delta G^{* E} \\
(\mathrm{~J} / \mathrm{mol})\end{array}$ & $\begin{array}{c}E \eta_{m} \\
(\mathrm{mPa} . \mathrm{s})\end{array}$ \\
\hline 0.0000 & 0.0000 & 0.0000 & 0.0000 & 0.0000 & 0.0000 \\
\hline 0.1220 & -0.0013 & 0.6521 & 0.0009 & 5.4632 & 0.0776 \\
\hline 0.2381 & -0.0021 & 1.0446 & 0.0017 & 9.5643 & 0.1342 \\
\hline
\end{tabular}


RASĀYAN J. Chem.

Vol. 11 | No. 2 |834 - 843 | April - June | 2018

\begin{tabular}{|c|c|c|c|c|c|}
\hline 0.3489 & -0.0026 & 1.2546 & 0.0023 & 12.6678 & 0.1714 \\
\hline 0.4546 & -0.0029 & 1.3039 & 0.0026 & 14.1194 & 0.1906 \\
\hline 0.5556 & -0.0030 & 1.2407 & 0.0026 & 14.6451 & 0.1932 \\
\hline 0.6522 & -0.0027 & 1.0909 & 0.0024 & 13.8550 & 0.1805 \\
\hline 0.7447 & -0.0023 & 0.8787 & 0.0020 & 11.5763 & 0.1538 \\
\hline 0.8334 & -0.0017 & 0.6174 & 0.0015 & 8.3527 & 0.1140 \\
\hline 0.9184 & -0.0010 & 0.3206 & 0.0008 & 4.3226 & 0.0625 \\
\hline 1.0000 & 0.0000 & 0.0000 & 0.0000 & 0.0000 & 0.0000 \\
\hline \multicolumn{6}{|c|}{$313.15 \mathrm{~K}$} \\
\hline 0.0000 & 0.0000 & 0.0000 & 0.0000 & 0.0000 & 0.0000 \\
\hline 0.1220 & -0.0011 & 0.6970 & 0.0011 & 6.2301 & 0.0684 \\
\hline 0.2381 & -0.0017 & 1.2749 & 0.0019 & 10.7777 & 0.1181 \\
\hline 0.3489 & -0.0023 & 1.5052 & 0.0025 & 13.6244 & 0.1507 \\
\hline 0.4546 & -0.0025 & 1.5964 & 0.0028 & 15.0172 & 0.1675 \\
\hline 0.5556 & -0.0025 & 1.5735 & 0.0028 & 15.4875 & 0.1696 \\
\hline 0.6522 & -0.0023 & 1.3605 & 0.0026 & 14.5735 & 0.1584 \\
\hline 0.7447 & -0.0019 & 1.1218 & 0.0022 & 12.4952 & 0.1348 \\
\hline 0.8334 & -0.0013 & 0.7757 & 0.0017 & 9.2867 & 0.0999 \\
\hline 0.9184 & -0.0007 & 0.4639 & 0.0010 & 5.2150 & 0.0547 \\
\hline 1.0000 & 0.0000 & 0.0000 & 0.0000 & 0.0000 & 0.0000 \\
\hline \multicolumn{6}{|c|}{$323.15 \mathrm{~K}$} \\
\hline 0.0000 & 0.0000 & 0.0000 & 0.0000 & 0.0000 & 0.0000 \\
\hline 0.1220 & -0.0008 & 0.7002 & 0.0013 & 7.1268 & 0.0607 \\
\hline 0.2381 & -0.0014 & 1.1104 & 0.0022 & 12.2754 & 0.1048 \\
\hline 0.3489 & -0.0018 & 1.3482 & 0.0027 & 15.2825 & 0.1336 \\
\hline 0.4546 & -0.0020 & 1.4323 & 0.0030 & 16.5139 & 0.1483 \\
\hline 0.5556 & -0.0020 & 1.3999 & 0.0030 & 16.5969 & 0.1501 \\
\hline 0.6522 & -0.0018 & 1.2433 & 0.0028 & 15.7404 & 0.1400 \\
\hline 0.7447 & -0.0015 & 1.0184 & 0.0024 & 13.8239 & 0.1191 \\
\hline 0.8334 & -0.0010 & 0.7397 & 0.0019 & 10.7130 & 0.0882 \\
\hline 0.9184 & -0.0005 & 0.3596 & 0.0012 & 6.8295 & 0.0483 \\
\hline 1.0000 & 0.0000 & 0.0000 & 0.0000 & 0.0000 & 0.0000 \\
\hline
\end{tabular}

Redlich-Kister polynomial of type ${ }^{7}$ given in equation 13 is used to fit the $\Delta \eta, \mathrm{V}^{\mathrm{E}}, \Delta n_{D}$, and $\Delta \mathrm{G}^{* E}$

$$
Y=x_{1} x_{2} \sum A_{i}\left(x_{1}-x_{2}\right)^{n}
$$

Where $n$ is the order of the polynomial, $\mathrm{A}_{\mathrm{i}}$ is the parameter coefficients acquired through equation 13 to experimental data using the regression method, and $Y=$ either $\mathrm{V}^{\mathrm{E}}, \Delta \eta, \Delta \mathrm{n}_{\mathrm{D}}$, or $\Delta \mathrm{G}^{* \mathrm{E}}$.

The standard deviation (S) is computed using the relation as given below: 
RASĀYAN J. Chem.

Vol. 11 | No. 2 |834 - 843 | April - June | 2018

$$
S(Y)=\left[\sum\left(A_{\exp }-A_{c a l}\right)^{2} /(N-n)\right]^{1 / 2}
$$

Where $n$-Number of coefficients and N-Number of data points. The Redlich-Kister parameter coefficients and the standard deviations (S) are presented in the Table-5.

Table-5: The Redlich-Kister parameter coefficients and Standard Deviations (S)

\begin{tabular}{|c|c|c|c|c|c|c|c|}
\hline $\mathrm{T} / \mathrm{K}$ & Property & $\mathrm{A}_{0}$ & $\mathrm{~A}_{1}$ & $\mathrm{~A}_{2}$ & $\mathrm{~A}_{3}$ & $\mathrm{~A}_{4}$ & $S$ \\
\hline \multirow{4}{*}{303.15} & $\Delta \eta(\mathrm{mPa} . \mathrm{s})$ & -0.0118 & -0.0004 & -0.0018 & 0.0004 & 0.0020 & 0.0643 \\
\hline & $\mathrm{V}^{\mathrm{E}} \times 10^{6}\left(\mathrm{~m}^{3} / \mathrm{mol}\right)$ & $\begin{array}{l}-0.0010 \\
\end{array}$ & 0.0178 & -0.0759 & 0.0071 & -0.0442 & 0.0112 \\
\hline & $\Delta \mathrm{G}^{*} \mathrm{E}(\mathrm{J} / \mathrm{mol})$ & 61.5723 & 4.8658 & -7.0037 & 1.3883 & 5.1853 & 0.1251 \\
\hline & $\Delta \mathrm{n}_{\mathrm{D}}$ & 0.0105 & 0.0007 & -0.0017 & 0.0014 & 0.0001 & 0.0002 \\
\hline \multirow{4}{*}{313.15} & $\Delta \eta(\mathrm{mPa} . \mathrm{s})$ & -0.0096 & -0.0002 & -0.0004 & 0.0010 & 0.0012 & 0.0648 \\
\hline & $\mathrm{V}^{\mathrm{E}} \mathrm{x} 10^{6}(\mathrm{~m} 3 / \mathrm{mol})$ & -0.0029 & 0.0044 & 0.0959 & -0.0605 & -0.0394 & 0.0114 \\
\hline & $\Delta \mathrm{G}^{*} \mathrm{E}(\mathrm{J} / \mathrm{mol})$ & 61.5364 & 5.0116 & 1.2374 & 2.4755 & 2.7240 & 0.1312 \\
\hline & $\Delta \mathrm{n}_{\mathrm{D}}$ & 0.0113 & 0.0006 & -0.0018 & 0.0017 & 0.0036 & 0.0002 \\
\hline \multirow{4}{*}{323.15} & $\Delta \eta(\mathrm{mPa} . \mathrm{s})$ & -0.0077 & 0.0000 & -0.0003 & -0.0001 & 0.0019 & 0.0654 \\
\hline & $\mathrm{V}^{\mathrm{E}} \mathrm{x} 10^{6}\left(\mathrm{~m}^{3} / \mathrm{mol}\right)$ & -0.0034 & -0.0139 & 0.1112 & -0.0765 & -0.1586 & 0.0115 \\
\hline & $\Delta \mathrm{G}^{*} \mathrm{E}(\mathrm{J} / \mathrm{mol})$ & 62.2999 & 5.2608 & 1.6719 & -2.6783 & 4.5755 & 0.1352 \\
\hline & $\Delta \mathrm{n}_{\mathrm{D}}$ & 0.0121 & 0.0000 & -0.0004 & 0.0030 & 0.0049 & 0.0001 \\
\hline
\end{tabular}

The random mixing mode ${ }^{11}$ and the interaction between the mixtures explain the volumetric behavior of studied binary liquid mixtures. It is noted that the excess molar volume is slightly tilted near the $\mathrm{CCl}_{4}$ rich region of the mole fraction for the system studied. The variances of excess molar volumes with the function of carbon tetrachloride composition $\left(x_{1}\right)$ at $\mathrm{T}(303.15$ to 323.15$) \mathrm{K}$ are shown in Fig.-1. It is noticed that $\mathrm{V}^{\mathrm{E}}$ are positive for all that the temperatures studied.

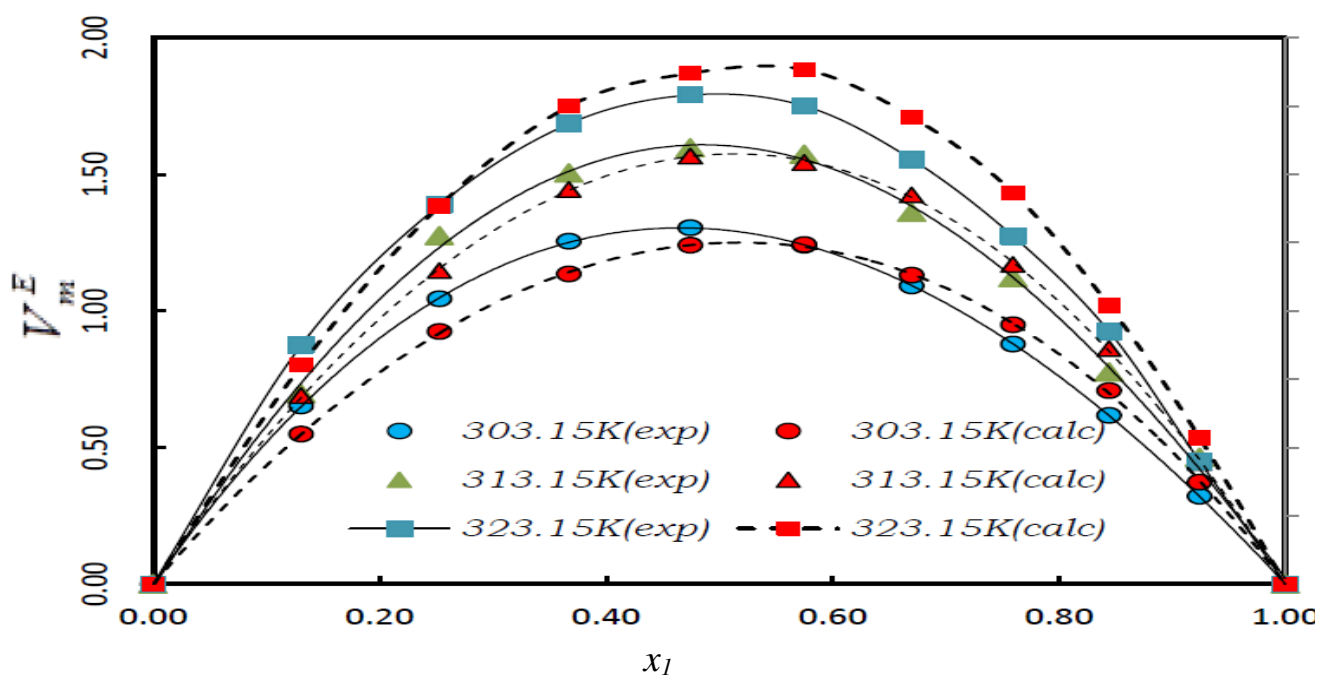

Fig.-1: Excess molar volumes $\left(\mathrm{V}^{\mathrm{E}}\right)$ against mole fraction of binary mixture carbon tetrachloride (1) + o-xylene (2) at $(303.15,313.15,323.15) \mathrm{K}$. 
The viscosity variation, with the function of the composition of component 1 is shown in Fig.-2 .Viscosity deviation $(\Delta \eta)$ is observed as negative for the carbon tetrachloride +0 -xylene mixture at all the temperatures that are studied in the present work. This is possibly attributed due to the presence of dipolar and dispersion forces among distinct molecules and linked to the variation in shape and size of distinct molecules.

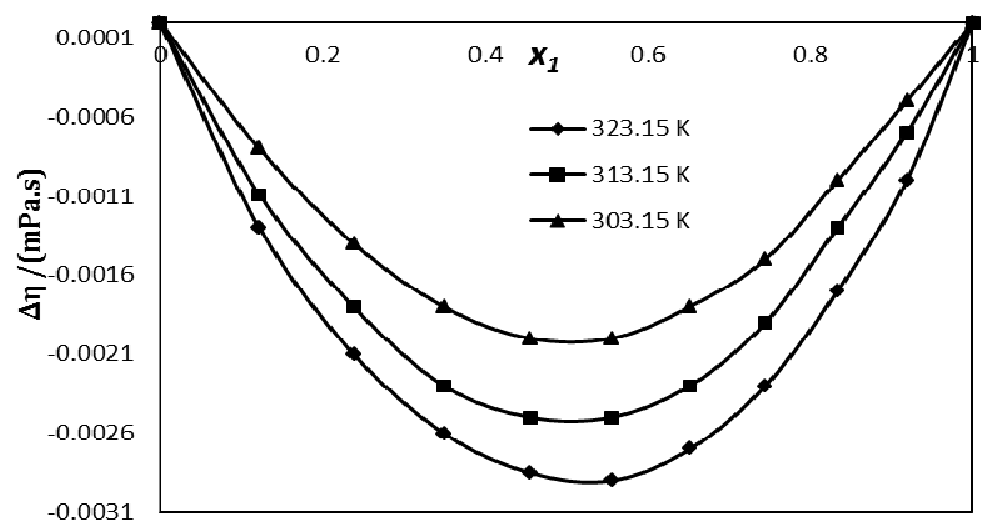

Fig.-2: Viscosity deviation $(\Delta \eta)$ against mole fraction of binary mixture carbon tetrachloride (1) + o-xylene (2) at $(303.15,313.15,323.15) \mathrm{K}$.

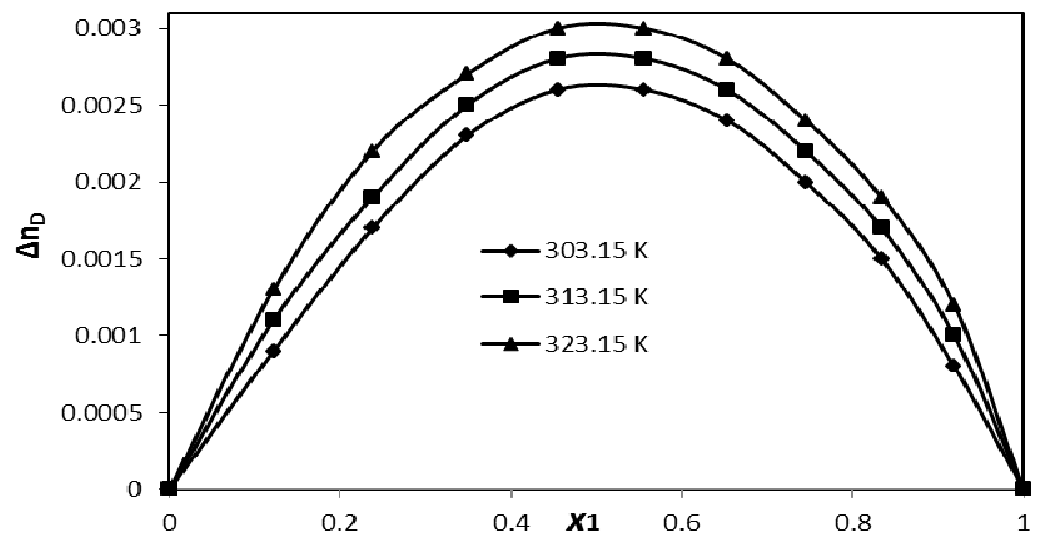

Fig.-3: Deviations in refractive indices $\Delta \mathrm{n}_{\mathrm{D}}$ against composition of carbon tetrachloride (1) + o-xylene (2) at $(303.15,313.15,323.15) \mathrm{K}$.

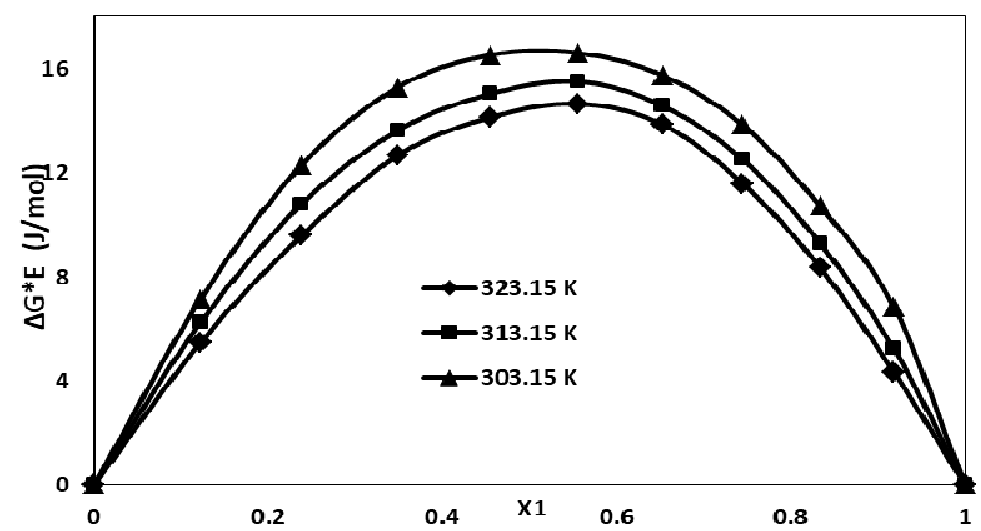

Fig.-4: Plot of $\Delta G^{* E}$ against the composition of carbon tetrachloride (1) + o-xylene (2) at $(303.15,313.15,323.15) \mathrm{K}$

It is also clear from the figure, with an increase in temperature ${ }^{11,15}$, the deviation in viscosity decreases. It is apparent that the variation of properties provides the clear evidence of the molecular contacts among 
the molecules in the systems which are helpful to examine and develop the thermodynamic models for computing and forecasting the fluid phase equilibrium.

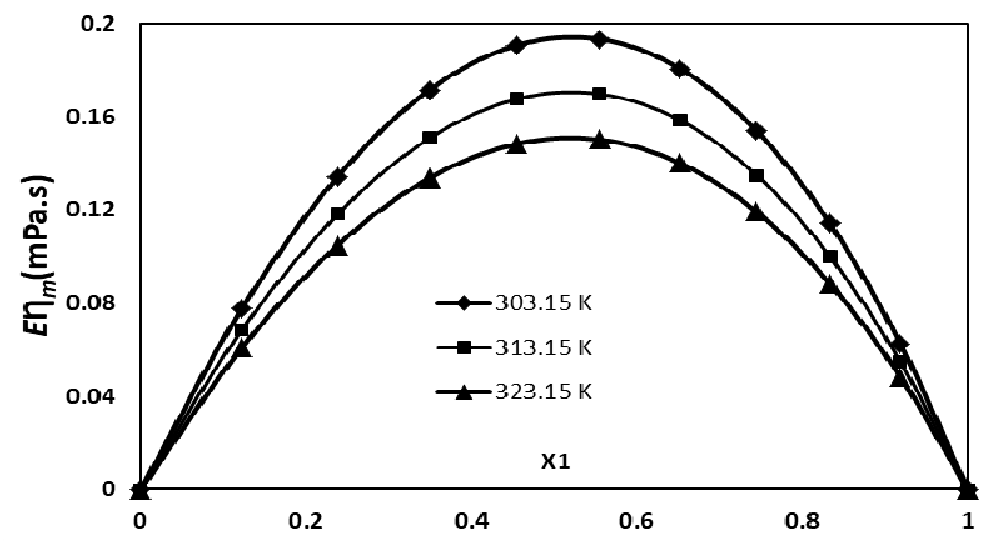

Fig.-5: Plot of $\mathrm{E}_{\mathrm{m}}$ against composition of carbon tetrachloride (1) + o-xylene (2) at $(303.15,313.15,323.15) \mathrm{K}$.

The refractive indices deviation versus $x_{1}$ for the carbon tetrachloride +0 -xylene at studied temperature is given in figure 3 . It is seen that the carbon tetrachloride + o-xylene system shows a positive deviation at all the temperatures studied. From figure $4, \Delta \mathrm{G}^{* E}$ can be used to perceive molecular interactions similar to viscosity deviations. For all the temperatures studied, $\Delta \mathrm{G}^{* E}$ was observed as positive values. To compute the activity coefficient of the liquid mixture, $\Delta \mathrm{G}^{* E}$ was used and the degree of $\Delta G^{* E}$ signifies the power of interaction among the dissimilar molecules ${ }^{23}$. Figure 5 shows that the $E \prod_{m}$ correlations at changed temperatures decline with an increase in temperature ${ }^{20,27}$ and viscosity correlation data obtained all are positive. Positive and negative values of G-N interaction parameters point out the occurrence of equally strong and weak contacts between distinct molecules.

\section{CONCLUSION}

Viscosities, densities, and refractive indices of binary mixtures were measured. Excess properties of liquid mixtures were found from the investigational outcomes and allied by the Redlich-Kister polynomial equations. The molecular interactions among the components were analyzed based on the experimental results. The viscosity deviation, changes in refractive indices, excess molar volume, and free energy activation of viscous flow for carbon tetrachloride and o-xylene system at diverse temperatures $(303.15 \mathrm{~K}$ to $323.15 \mathrm{~K})$ is reported. It is observed from the study that there is intermolecular contact exists between the components in the binary mixture.

\section{REFERENCES}

1. Veeraswamy Jaana and Satyanarayana Nallani, Rasayan J. Chem., 1, 602(2008).

2. A. Mchaweh, A. Alsaygh, and M. A. Mosh-Feghian, Fluid Phase Equilib., 224,157(2004), DOI:10.1016/j.fluid.2004.06.054

3. K. Saravanakumar, D. Venkatesan and M. Gokulakrishnan, Res. J. Pharm., Biol. Chem. Sci., 5, 1392(2014).

4. S. R. Patil, U.G. Deshpande and A. R. Hiray, Rasayan J. Chem., 3, 66(2010).

5. R. R. Zoting, K. V. Pawar and U. E. Choudhari, Rasayan J. Chem., 7,410(2014).

6. K. Saravanakumar, R. Baskaran and T. R. Kubendran, Russ. J. Phys. Chem., A.86, 1947(2012).

7. A. Redlich, T. Kister, Ind. Eng. Chem., 40,345(1948), DOI:10.1021/ie50458a036

8. D. Perrin, W. L. F. Armerego, Purification of Laboratory chemistry, $3^{\text {rd }}$ Ed. Pergamon Press, Oxford 89, 98(1988)

9. J. A. Riddick, W. B. Bunger, T. K. Sakano, Wiley-Interscience: New York, $4^{\text {th }}$ Ed.125-129,(1986). 
RASĀYAN J. Chem.

Vol. 11 | No. 2 |834 - 843 | April - June | 2018

10. Prem P Singh., Meenu Bhatia., Maken S., Indian J Chem., Sect A, 29, 263(1990)

11. Hai-Lang Zhang, J. Chem. Eng. Data, 48, 52(2003), DOI:10.1021/je020493i

12. Surabhi Varshney., and Mukhtar Singh., J. Chem. Eng. Data, 51, 1136(2006), DOI: $10.1021 / \mathrm{je} 0600303$

13. S. L. Oswal, R. L. Gardas and R. P. Phalak, Thermochim. Acta, 426, 199(2005), DOI:10.1016/j.tca.2004.08.001

14. Oana Ciocirlan and Olga Iulian., J. Serb. Chem. Soc., 74,317(2009), DOI:10.2298/JSC0903317C

15. Aminabhavi Tejraj M., Kamalika Banerjee, J. Chem. Eng. Data, 43,1096(1998), DOI:10.1021/je980145+

16. M. V. Rathnam, Sudhir Mohite, J. Chem. Eng. Data, 50,325(2005), DOI:10.1021/je0400052

17. Sangita Sharma., Khushbu Thakkar, Paras Patel, and Madhuresh Makavana, Advances in Physical Chemistry, 93,12(2013), DOI:10.1155/2013/932103

18. Ezekiel Dixon Dikio., Orient. J. Chem., 30,953( 2014), DOI:10.13005/ojc/300306

19. Bal Raj Deshwal., Anu Sharma., Krishan Chander Singh., Chin. J. Chem. Eng., 16, 599 (2008), DOI: 10.1016/S1004-9541(08)60127-5

20. John George., Nandhibatla V. Sastry, J. Chem. Eng. Data, 48 ,1529 (2003), DOI:10.1021/je0340755

21. Ch. Praveen Babu., Pavan Kumar G., Samatha K., Int. J. Adv. Sci. Tech., 76,27(2015), DOI: 10.14257/ijast.2015.76.04

22. Arvind R. Mahajan and Sunil R. Mirgane. Journal of Thermodynamics, 25,75(2013) DOI: $10.1155 / 2013 / 571918$

23. Ezekiel D. Dikio., Simphiwe M. Nelana., David A. Isabirye. Eno E. Ebenso., Int. J. Electrochem Sci., 7, 1110, (2012).

24. R. K. Hind, E. McLaughlin, A. R. Ubbelohde, T. Faraday Soc., 56, 328(1960), DOI: 10.1039/TF9605600328.

25. Luis F. Sanz., Juan A. González., Isasías García de la Fuente., José C. Cobos., J. Chem. Thermodyn. 80, 161(2015), DOI:10.1016/j.jct.2014.09.005

26. R. I. Bearman, P. F. Jones, J. Chem. Phys.,12, 1432(1960), DOI: 10.1063/1.1731424

27. Xin-Xue Li., Gui-Chen Fan., Yan-Wei Wang., Min Zhang., Yi-Qiang Lu., J. Mol. Liq., 151, 62 (2010), DOI:10.1016/j.molliq.2009.11.005

[RJC-2094/2018] 